\title{
Connecting the Dots: \\ Pre-existing Patterns of Gender Inequality and the Likelihood of Widespread and Systematic Sexual Violence
}

\author{
Sara E. Davies and Jacqui True ${ }^{1}$
}

In this article we explore the relationship between pre-existing patterns of gender inequality and the occurrence of widespread and systematic sexual and gender based violence (SGBV). We ask three questions: What do we know about the status of gender inequality in high-risk situations prior to the outbreak of atrocities (which include SGBV)? What can be done to understand the relationship between systemic gender inequality and the use of sexual violence in the particular high-risk situations? And what long-term approaches are necessary to prevent SGBV?

The 1998 Rome Statute of the International Criminal Court (ICC) is the first international instrument to include widespread and systematic sexual and genderbased $^{2}$ violence as acts of crimes against humanity and/or war crimes committed in international and non-international armed conflicts. ${ }^{3}$ Sexual violence includes including rape, sexual slavery, enforced prostitution, forced pregnancy, enforced sterilisation, and other forms of sexual violence - while gender-based violence includes acts of persecution based on gender as a crime against humanity; and they may also fall under the Court's jurisdiction if they constitute acts of genocide or war crimes (Office of the ICC Prosecutor 2014: 5). ${ }^{4}$ These crimes can occur outside or inside the 'theatre of war'. The Rome Statute builds upon a history of rape prohibition that began under the 1863 Lieber Code where rape was explicitly prohibited and punished by death and the 1907 Hague Convention Respecting the Law and Custom of War on Land. 5

\footnotetext{
${ }^{1}$ Sara E. Davies, Griffith University, sara.davies@griffith.edu.au; Jacqui True, Monash University, jacqui.true@monash.edu. We thank Elliot Dolan-Evans for his research assistance. The research for this article was supported by the Australian Research Council Discovery Project funding scheme (DP 140101129).

2 Valerie Oostervald, "The Definition of "Gender" in the Rome Statute of the International Criminal Court: A Step Forward or Back for International Criminal Justice?', Harvard Human Rights Journal 18: 1 (2005), 55-84.

${ }^{3}$ We adopt the recommendations of the Office of the ICC Prosecutor, that SGBV may be used instrumentally and rationally without being 'strategic' in the sense of a commanded military tactic and that an act of sexual violence may not need to be widespread or systematic but may be an act that forms part of a broader widespread and systematic attack on a civilian population (Office of the ICC Prosecutor 2014: para.32, p.18). See also: Eleni Coundouriotis. "'You Only Have Your Word:" Rape and Testimony, Human Rights Quarterly 35:2 (2013): 365-385.

${ }^{4}$ Office of the ICC Prosecutor, Policy article on sexual and gender-based crimes, (Hague:

International Criminal Court, 2014), 5. Available at: https://www.icc-cpi.int/iccdocs/otp/OTPPolicy-Article-on-Sexual-and-Gender-Based-Crimes--June-2014.pdf

${ }^{5}$ Kelly Dawn Askin, War Crimes against Women: Prosecution in International War Crimes Tribunals (The Hague/Boston: Martinus Nijhoff Publishers, 1997), 42; Vincent Bernard, 'Sexual
} 
Along with the Rome Statute, crimes of sexual and gender based violence are also referred to in United Nations (UN) Security Council Resolution 1820 (2008). That resolution declared sexual violence a threat to international peace and security. Concurrently the threat of conflict-related sexual violence is also recognised by the annual UN Secretary-General report on sexual violence in armed conflict situations, and in the 2013 UN General Assembly Declaration on the Commitment to End Sexual Violence in Conflict. ${ }^{6}$ At the adoption of Security Council Resolution (SCR) 1325 in 2000, the Security Council called for an "immediate and complete cessation by all parties to armed conflict of all acts of sexual violence against civilians", considered crimes under the 1998 Rome Statute. ${ }^{7}$ In SCR 1820 (2008) and subsequent Security Council resolutions on sexual violence, the $\mathrm{UN}$ and member states are expected to take a series of measures - from developing an early warning matrix, to listing perpetrators and reporting situations to the Council, to the attachment of sanctions to individuals and armed groups suspected of these crimes. ${ }^{8}$ States and peacekeeping forces are responsible for the protection of civilians when they are subjected to SGBV, whether by state or non-state actors. ${ }^{9}$ All parties to conflict must take SGBV allegations seriously. They must assist with the collection of evidence to investigate and prosecute sexual violence perpetrators, and address the culture of impunity that enables these acts of violence, while also providing services for victims. ${ }^{10}$ There is also the initiative to publicly 'name and shame' perpetrators by the attachment of lists of individuals and groups suspected of these crimes to annual Secretary General reports on situations of sexual violence. ${ }^{11}$ The same resolution that recommended the inclusion of individual and groups on annual reports of sexual violence, Resolution 1960 (2010),12 also called for the UN Office of the Special Representative on Sexual Violence to report all suspected or confirmed incidences of widespread and systematic SGBV in conflict-related

Violence in Armed Conflict: From Breaking the Silence to Breaking the Cycle', International Review of the Red Cross 96: 984 (2014), 431.

${ }^{6}$ S/Res/1820 (2008); UN Security Council, Report of the Secretary-General on Sexual Violence in Conflict, 13 January 2012, S/2012/33; UN General Assembly, Declaration of Commitment to End Sexual Violence in Conflict, 24 September 2013.

${ }^{7}$ S/Res/1325 (2000), para.9, 10 and 11.

${ }^{8}$ S/Res/1820 (2008); S/Res/1888 (2009); S/Res/1889 (2009); S/Res/1960 (2010); S/Res/2106 (2013).

${ }_{9}^{9}$ S/Res/1820, para.3, 4 and 8.

10 Ibid.

${ }^{11}$ Gina Heathcote, 'Naming and Shaming: Human Rights Accountability in Security Council Resolution 1960 (2010) on Women, Peace and Security', Journal of Human Rights Practice 4:1 (2012).

12 S/Res/1960 (2010). 
situations to the Security Council through the UN Secretary-General. ${ }^{13}$ Contemporary scholarship on SGBV and the effectiveness of l prevention strategies have been informed by these UN Security Council developments in declaring sexual violence situations of concern. ${ }^{14}$

Prevention of widespread and systematic SGBV crimes - as with all early warning analysis to prevent conflict and genocide ${ }^{15}$ - requires engagement with the 'contributing political, social and economic context,' which frequently provides signals of trouble ahead. ${ }^{16}$ The 'warning-response gap' is a phrase often used to describe the effectiveness of early warning. ${ }^{17}$ The state of knowledge, technology and precedent means that there is little that is not known about high-risk situations today. That is, the likelihood of a situation tipping towards atrocities is often well established. Yet, there remains uncertainty about the best tools and practices to prevent escalation. Some contend this 'warning-response' gap tends to result in the international community falling back on reacting and responding to crises rather than preventing them in the first place. 18 Reaction and response, in the character of peacekeeping or political missions can be

\footnotetext{
${ }^{13} \mathrm{~S} / 2012 / 33, \mathrm{p} .2-3$.

${ }^{14}$ Maria Eriksson Baaz and Maria Stern, Sexual Violence as a Weapon of War? Perceptions, Prescriptions, Problems in the Congo and Beyond (London: Zed Books, 2013); Dara Kay Cohen and Ragnhild Nordas, 'Sexual Violence in Armed Conflict: Introducing the SVAC Dataset, 1989-2009', Journal of Peace Research, 51: 3 (2014), 418-428; Catherin O'Rourke, Fionnuala Ni Aolain, and Aisling Swaine, 'Transforming Reparations for Conflict-Related Sexual Violence: Principles and Practice',Harvard Human Rights Journal 28 (2015): 97-146.

${ }^{15}$ Gregory H. Stanton, 'Could the Rwanda genocide have been prevented?', Journal of Genocide Research 6:2 (2014); 211-228; Elise Von Joeden-Forgey, 'Gender and the future of genocide studies and prevention'. Genocide Studies and Prevention 7 (2012), 89-107; I. William Zartman, Preventing Deadly Conflict (Cambridge: Polity, 2015).

${ }^{16}$ UN Secretary-General, Report of the Secretary-General Implementing the Responsibility to Protect, 12 January 2009. A/63/677, 6.

${ }^{17}$ Alexander L. George and Jane E. Holl, The Warning-Response Problem and Missed Opportunities in Preventive Diplomacy, A Report to the Carnegie Commission on Preventing Deadly Conflict (New York: Carnegie Corporation of New York, 1997); for an alternative conceptualisation of the problem see, Christopher O. Myer, Florian Otto, John Brante and Chiara De Franco, 'Recasting the Warning-Response Problem: Persuasion and Preventive Policy', International Studies Review 12 (2010), 556-578.

18 Séverine Autesserre, "The responsibility to protect in Congo: the failure of grassroots prevention', International Peacekeeping 23: 1 (2016), 29-51; Francisco Mancini and Marie 0 'Reily, New Technology and the Prevention of Violence and Conflict (New York: International Peace Institute, UNDP, and USAID, 2013). https://sipa.columbia.edu/faculty/francescomancini\#sthash.htFbfFZu.dpuf
} 
effective. ${ }^{19}$ However, this is not prevention. Prevention means action that anticipates and stops displacement, destruction, and mass atrocities well in advance. ${ }^{20}$

The prevention of atrocity crimes requires efforts directed at 'structural prevention',21 'direct prevention',22 and 'escalation prevention'. In the case of SGBV, we contend that there is a need for a gender-sensitive perspective on mass atrocity prevention. SGBV crimes occur where there are existing social, economic, and political grievances, and gender inequality is likely to cut across those grievances. However, acknowledging the widespread presence of gender inequality is not the same as adopting a gendersensitive perspective on existing frameworks for atrocity prevention. In this article we show why structural gender inequality must be the necessary fourth condition of all prevention frameworks (after structural, direct, and escalation prevention) to address the prevalence and likelihood of SGBV. SGBV is deployed to oppress individuals and groups engendering generalised silences, impunity, and stigma against those who are targeted, whether they are boys and men or girls and women. ${ }^{23}$ There are distinct opportunities and incentives for the perpetration of sexual and gender-based violence that are rooted in two conditions: 1) gender inequality in that society and 2) violations of the body often in private (versus public) spaces. ${ }^{24}$ We predict that the more gender inequity there is in a society, the more likely that society is to experience widespread and systematic SGBV. Silence, impunity and stigma are crucial preconditions for SGBV. These conditions make collecting reports and testimonies of SGBV extremely difficult,

\footnotetext{
${ }^{19}$ Kyle Beardsley, Kyle and Kristian Skrede Gleditsch, 'Peacekeeping as Conflict Containment'. International Studies Review 17: 1 (2015), 67-89; Lisa Hultman, Jacob D. Kathman, and Megan Shannon, 'United Nations Peacekeeping dynamics and the duration of post-civil peace', Conflict Management and Peace Science (2015).

${ }^{20}$ Eli Stamnes, 'Speaking R2P' and the Prevention of Mass Atrocities, Global Responsibility to Protect 1: 1 (2009), 70-89.

${ }^{21}$ Structural conditions defined as, at a minimum, the presence of intergroup competition and conflict, and the presence of political, economic, and/or social grievances, a preparedness and capacity (of at least one party) to use violence and violate human rights, and a perceived absence of legitimate pathways for nonviolent conflict resolution. See Alex J. Bellamy Alex J. Bellamy. Mass Atrocities and Armed Conflict: Links, Distinctions, and Implications for the Responsibility to Prevent, The Stanley Foundation Policy Brief, February (2011), 5. http://acme.highpoint.edu/ msetzler/IntlSec/IntlSecReads/Old_IntSecReads/GenocideStanley0 211.30.pdf

${ }^{22}$ The intersection of multiple structural conditions may include a context where group rivalry is animated by perceived horizontal inequalities, the problem is unlikely to be solved without some improvement in the real economic, social, and political opportunities open to group members. See Bellamy (2011). Mass Atrocities and Armed Conflict,, 4.

${ }^{23}$ Sara E. Davies, Jacqui True and Maria Tanyag. 'How women's silence secures the peace: analysing sexual and gender-based violence in a low-intensity conflict', Gender \& Development 24: 3 (2015), 459-473

24 UN Secretary-General. Conflict related sexual violence. Report of the Secretary General. S/2012/33. 13 January (2012), 5.
} 
particularly for prevention purposes. Knowledge of the incidence of sexual and genderbased violence primarily relies on situations where it has already taken place. ${ }^{25}$ Further, data collection and datasets focused on early warning have (for the last two decades of their development) have relied on reports to inform knowledge about violence including 'sexual and gender-based violence' where very few reporting frameworks reference women or gender at all (11 indicators out of 832 according to one study). ${ }^{26}$ Given the data limitations concerning context-specific societal gender relations; historical cases of SGBV may or may not help us understand the 'early warning' relationship between the scale and type of sexual violence reported and the status of gender in any given site.

In this article we examine contemporary cases of widespread and systematic SGBV (reported to the UN Security Council) as evidence of the need to shift the focus of SGBV response from reaction to prevention. A SGBV prevention focus, we argue, requires greater attention to the cases where the leap from generalised gendered violence to gendered atrocities appears to be a 'logical' continuum when triggered by extreme political conditions. ${ }^{27}$ The first part of the article explores the current constraints in building a timely, early warning database on widespread and systematic SGBV. The second part examines how much of the focus has been on reactionary responses to SGBV situations, the result of a general pattern where atrocities start to take place before action is enabled. We examine why these responses to SGBV are necessarily limited because they are not technically prevention but a form of immediate protection. The third part argues that improving our analysis of discriminatory and unequal political, social and economic conditions from a gender-sensitive perspective may suggest situations of concern for SGBV before they happen. With this knowledge, prevention-

\footnotetext{
${ }^{25}$ Kathryn Farr, Extreme War Rape in Today's Civil-War-Torn States: A Contextual and Comparative Analysis, Gender Issues 26 (2009), 1-41; Susan Dewey and Tonia St. Germaine, 'Between Global Fears and Local Bodies: Toward a Transnational Feminist Analysis of ConflictRelated Sexual Violence', Journal of International Women's Studies, 13: 3 (2012), 49-64; Monica M. Alzate, 'The sexual and reproductive rights of internally displaced women: the embodiment of Colombia's crisis', Disasters 32 (2008): 131-148.

26 UN Women. Gender-Responsive Early Warning: Overview and How-to Guide (2012), 4.

27 The 1998 Rome Statute of the International Criminal Court (ICC) defines widespread and systematic sexual and gender-based crimes to include rape, sexual slavery, enforced prostitution, forced pregnancy, enforced sterilisation, and other forms of sexual violence, Office of the ICC Prosecutor 2014: 5. These crimes may occur in conflict or not. However, the UN Security Council is primarily concerned with hearing reports of sexual violence being directed, ordered, or permitted by organized groups against populations in conflict situations recognised by the Council. The UN Secretary-General has and may report cases, whether in conflict or not, that meet the 'widespread and systematic' criteria, UN Secretary-General, S/2016/361, 2. The situations reported are different to national-level 'Violence Against Women' reports which refer to violence that affects women and girls disproportionately but may not be widespread.
} 
focused programs targeted at gendered institutional and social inequality in specific cases may be able to avert at least some atrocities. However, developing such programs based on the indications rather than the certainty of risk may lead to widespread and systematic SGBV not 'playing out'. But that is the main objective of SGBV prevention. Moreover, we argue that these programs have win-win outcomes not only for women's participation in local economic, political and social institutions, but for the broader population of states because improving gender relations and empowering at-risk groups reduces atrocity risk and increases equitable economic productivity and community wellbeing.

\section{Problem: what we know, what we don't know}

Sexual and gender-based violence (SGBV) remains a silent and hidden crime. Nonreporting is frequently the norm for a vast range of reasons that include: the stigma and shame experienced by victims of this form of violence, the politics and dangers associated with reporting it, the lack of robust institutions to report to, the broader culture of impunity for reporting, and the practical difficulties encountered in examining and compiling reports on SGBV in the field. ${ }^{28}$ These challenging conditions to report SGBV effectively enhances the power and purpose of this type of violence. ${ }^{29}$

Reporting constraints are compounded by endemic gender oppression within groups and societies. ${ }^{30}$ Even in situations where humanitarian access is unrestricted and documentation of SGBV is taking place, reports may be the tip of iceberg in terms of actual violence. ${ }^{31}$ Moreover, in politically sensitive situations, if international organizations doubt their capacity to effectively extend protection they will not encourage or document reporting. ${ }^{32}$ Likewise individuals will not come forward and

\footnotetext{
${ }^{28}$ For example, see collection of articles in the International Review of the Red Cross, 96 (894) 2014.

${ }^{29}$ Janine Natalya Clark, 'Making Sense of Wartime Rape: A Multi-causal and Multi-level Analysis', Ethnopolitics, 13: 5 (2014), 461-482.

${ }^{30}$ Monica McWilliams and Fionnuala Ni Aolain, "There is a War Going on You Know": Addressing the Complexity of Violence Against Women in Conflicted and Post Conflict Societies, Transitional Justice Review 1:2 (2013), 4-44; Jo Spangaro, Chinelo Adogu, Geetha Ranmuthugala, Gwaine Powell Davies, Lea Steinacker and Anthony Zwi, 'What Evidence Exists for Initiatives to Reduce Risk and Incidence of Sexual Violence in Armed Conflict Other Humanitarian Crises? A Systematic Review, PLOS One 8:5 (2013)..

31 Emily Rosser, The Messy Practice of Building Women's Human Rights: Truth-telling and Sexual Violence in Guatemala, Latin American Policy 6 (2015), 68-88.

32 Office for the Coordination of Humanitarian Affairs (OCHA). 2015. GenCap Contribution to the Global Study on SC Resolution 1325 on Women, Peace and Security. 2 September.
} 
disclose the violence that they have suffered if their safety and anonymity is not assured. ${ }^{33}$

Outside of conflict and atrocity situations, gender-based violence (GBV) - primarily perpetrated against girls and women by known and unknown perpetrators - produces similar reporting constraints. A study by Tia Palermo, Jennifer Bleck, and Amber Peterman found that the social, legal and financial constraints on reporting GBV in developing countries meant that knowledge of incidence and prevalence was only the 'tip of the iceberg' in terms of the real extent of the crimes being perpetrated. ${ }^{34}$

In both situations of widespread and systematic SGBV and GBV, men may face additional social and political stigmas in reporting their experience of such violence, remaining accepted in their informal network, and receiving appropriate care and treatment. 35 Overwhelmingly however, despite the reporting limitations described above, there remains confidence that women still account for the large majority of population more likely to suffer widespread and systematic SGBV and GBV, to suffer serious physical and reproductive injury, experience high levels of social rejection from their informal networks, which also impacts on their economic security as well as their potential displacement and vulnerability to subsequent violence. ${ }^{36}$

The 2016 UN Secretary-General reports on SGBV noted that gender injustices are, unequivocally, indicators for early warning and prevention of atrocities:

https://www.humanitarianresponse.info/en/coordination/gencap/document/gencapcontribution-global-study-sc-resolution-1325-women-peace-and (Accessed November 9, 2015). ${ }^{33}$ Care France, '"The Girl Has No Rights": Gender-based violence in South Sudan', May 2014. http://www.carefrance.org/ressources/themas/1/3958,CARE_The-Girl-Has-No-Rights_GBV-in.pdf

34 Tia Palermo, Jennifer Bleck, and Amber Peterman, 'Tip of the iceberg: Reporting and gender based violence in developing countries', American Journal of Epidemiology, 179: 5 (2014), 602612. In survey questionnaires across the Americas and Caribbean, Africa, India and East Asia, Central Asia and Eastern European, the study found that nearly half (40\%) of all women who have experienced GBV will report it to an informal source (family, friends, partner, neighbour) but only $7 \%$ of women surveyed will report to a formal source (police, health clinic, religious leader, etc.).

${ }^{35}$ Chris Dolan, 'Letting go of the gender binary: Charting new pathways for humanitarian interventions on gender-based violence', International Review of the Red Cross 96 (2014), 485501; Ellen Anna Philo Gorris, 'Invisible victims? Where are male victims of conflict-related sexual violence in international law and policy?', European Journal of Women's Studies 22: 4 (2015), 412427.

36 Tia Palermo, Jennifer Bleck, and Amber Peterman, 'Respond to "Disclosure of Gender-Based Violence”', American Journal of Epidemiology, 179: 5 (2014), 619-620. 
The ever-present threat of sexual assault compels women to lead highly circumscribed lives in militarized zones, as seen in eastern Afghanistan or northern Sri Lanka. Moreover, high-profile women across a range of professions have been subjected to sexual harassment and humiliation aimed at silencing them. In this way, sexual violence serves as a tool of social and moral control to relegate women to the private sphere and to punish perceived "countercultural" behaviour...Historically, misogynistic media propaganda and crackdowns on women's rights and freedoms have presaged the use of sexual violence as a tactic of war, terrorism and political repression. This underscores the strategic value of gender analysis in all atrocity-prevention efforts. ${ }^{37}$

Despite this acknowledgement of the connections between gendered oppression and the use of SGBV, it is difficult to discern with gender analysis when and how situation shifts from a 'warning' for atrocities to the need for a concerted 'response' (whether sanctions, referral to the ICC, or escalated program delivery with women protection advisors). Some researchers argue that the pervasiveness of structural gender inequality across conflict, post-conflict and politically unstable environments makes it a poor tool for distinguishing between situations of concern for escalating SGBV and situations of endemic, rather than heightened violence. Yet, annual reports by the Secretary-General and the early warning mechanism frameworks developed by UN Women, call for attention to the gender inequality conditions and endemic levels of violence against women to inform interventions to prevent high risk of mass atrocities including SGBV.

Three tentative patterns characterise widespread and systematic SGBV: First, women and girls still account for the majority of victims; Second, the use of SGBV to terrorise, 'cleanse', and fracture societies is effective precisely because of the contextual status of gender inequality in that society; 38 Third, a culture of impunity for GBV suggests that there will be few reliable and unbiased reports available to inform and guide international response and action when widespread and systematic SGBV occurs. ${ }^{39}$ Despite these known patterns, in situations where there is often no Security Council consensus on the need for briefings (let alone action), a 'wait and see' rather than an active prevention approach is the norm. Further, in situations where political tensions may already presage caution, SGBV in so far as it relies on secrecy and stigma, produces a potent effect against populations and essentially undermines the chances to prevent these crimes.

\footnotetext{
37 UN Secretary-General, S/2016/361, 6 (emphasis added).

${ }^{38}$ UN Secretary-General, Conflict Related Sexual Violence: Report of Secretary-General, S/2015/203, 23 March 2015.

${ }^{39}$ Bernard, Sexual Violence in Armed Conflict: From Breaking the Silence to Breaking the Cycle'.
} 
Awareness of the lack of reporting of SGBV and the significant constraints on reporting this type of violence has led to efforts to document and observe patterns of widespread and systematic SGBV. Since the adoption of Security Council Resolutions 1820 (2008) and 1888 (2009) the UN Secretary-General has annually reported (2010-2015) 'information on parties to conflict credibly suspected of committing or being responsible for acts of rape and other forms of sexual violence'; and on current country situations of concern for sexual violence. ${ }^{40}$ In 2016, 19 country situations were reported and 48 parties (majority are non-state armed groups) were reported in the Annex list of perpetrators. Similar to prior annual reports, the 2016 report notes: "Practitioners in the field estimate that for each rape reported in connection with a conflict, 10 to 20 cases go undocumented. The figures presented here reflect incident reports and therefore do not indicate the magnitude of the problem." 41

There remain significant challenges with SGBV data collection that are inextricable from the contexts of gender oppression. These challenges affect scholarly research, which often relies on secondary reports of sexual violence in conflict situations to understand patterns of widespread and systematic SGBV, as well as policymaking. UN prevention, for instance, is often limited to reactions to reporting in conflict-affected situations, which are already of interest to the Security Council even where there is strong evidence of SGVB occurring from UN field office reports.. ${ }^{42}$ The policy dilemma then centres on

\footnotetext{
${ }^{40}$ Sexual violence is defined as rape, sexual slavery, forced prostitution, forced pregnancy, enforced sterilisation and 'any other form of sexual violence of comparable gravity perpetrated against women, men, or children with a direct or indirect (temporal, geographic or causal) link to a conflict', UN Secretary-General, Conflict Related Sexual Violence: Report of the SecretaryGeneral, S/2013/149, 14 March 2013, 2. The 2013 report goes on to note that 'link to a conflict' may be 'evident in the profile and motivations of the perpetrator, the profile of the victim, the climate of impunity or State collapse, any cross-border dimensions or violations of the terms of a ceasefire agreement'. Furthermore, emerging concerns can also include sexual violence against men and boys, 'plight of children' born as a result of rap, the practice of forced marriage by armed groups; also the 'nexus between sexual violence and the illicit extraction of natural resources, the displacement of civilian populations, and the inadequacy of disarmament, demobilization and reintegration and security sector reform efforts'. S/2013/149, 2.

${ }^{41} \mathrm{~S} / 2016 / 361,3$.

${ }^{42}$ See, for example the finding of an internal review of UN Action, 2007-2012 (Inter-Agency Standing Committee for Conflict Related Sexual Violence):

"Interviewees who work very much from a GBV perspective grounded in the context of the IASC and the humanitarian cluster arrangements, have said however that they do feel that CRSV being on the Security Council agenda has increased the focus on GBV more widely. The assignment of 'gender' to CRSV also influenced the debates about whether men and boys were sufficiently considered as victims and survivors and if the focus tended to be gender interpreted as women and girls. One also has to add to these definitional tensions the persistence of sceptics and deniers inside and outside the UN who still have not accepted the case for CRSV as a peace and security issue or indeed as nothing more than an inevitable casualty of war." Eleanor O'Gorman, Review of UN Action Against Sexual Violence in Conflict 2007-2012: Final Report. January 2013, 13. http://www.stoprapenow.org/uploads/advocacyresources/1401281502.pdf
} 
what to prioritise in efforts to respond to situations of sexual and gender-based violence against civilians. In the next section, we discuss the three major approaches, to date, that respond to, rather than prevent, SGBV.

\section{Approach: what is to be done}

In the search for patterns across the reported cases of widespread and systematic SGBV, especially structural patterns of gender-based inequality and violence (GBV), to identify situations of 'emerging' risk of SGBV we aim to locate the tipping point for large scale, coordinated SGBV attacks. To date, attempts to locate this tipping point have circled around three options.

First, preventing the opportunity to rape. The opportunity to use large scale sexual violence to terrorise, cleanse, and fracture societies is encouraged by the absence of laws and rules that strictly prohibit such violence within societies and armed groups. ${ }^{43}$ Codes of conduct within the military, sanctions against perpetrators, the introduction of national legislation prohibiting a broad range of sexual crimes, and the refusal to grant amnesty for sexual violence crimes in ceasefire and peace settlements are measures often absent in situations where widespread and systematic SGBV has occurred. The prevailing response then is to confront the state and non-state institutions that may condone and/or permit such violence. Vital future prevention strategies include; at the international level, persuasive tools such as 'name and shame' reports like the annual SRSG reports on sexual violence and retributive tools such as referral to the ICC for SGBV crimes; and at the national level, the creation of legal clinics within conflict zones, and emphasis on no amnesty for SGBV crimes in negotiated ceasefires and peace agreements. . ${ }^{44}$ Essentially, the pursuit of a 'rule of law' approach is informed by an opportunistic understanding of why SGBV occurs (that ism it primarily happens because it canm as opposed to it happens because it is effective in achieving the goals of conflict parties).

\footnotetext{
${ }^{43}$ Dara Kay Cohen, Amelia Hoover Green, and Elisabeth J Wood, 'Wartime Sexual Violence: Misconceptions, Implications, and Ways Forward', February (Washington: United States Institute of Peace, 2013).

${ }^{44}$ Foreign Commonwealth Office. International Protocol on the Documentation and Investigation of Sexual Violence in Conflict (London: UK Government, 2014); Ni Aoilan et al, Transforming Reparations for Conflict-Related Sexual Violence.
} 
A second option has been reaction to events as they occur through the Security Council. Since the adoption of Security Council Resolution 1820, the use of sexual violence as a threat to international peace and security has legitimised the regular inclusion of this crime in country-specific UNSC resolutions. This means that missions - both political and peacekeeping - have been regularly charged with responsibility for reporting crimes of sexual violence and since Resolution 1960, for bringing these crimes to the Security Council as justification for the Council's direct action to end these crimes through sanctions, inquiry, referral to the ICC, deployment of Women Protection Advisors or enhanced deployment, of peacekeepers. ${ }^{45}$ The pattern that is understood by the Security Council - and illustrated in successive WPS resolutions - is that sexual violence is a 'weapon' used to effectively remove and control populations, as well as to increase control over resources, land, and borders. ${ }^{46}$ According to this frame, sexual violence is a weapon easily used and will continue until the desired ends are achieved or the protection of civilians is directed by the Security Council through a peacekeeping force, stabilisation mission, or referral to the ICC. In practice, the Security Council has a mixed record of being proactive in taking action in situations where human rights violations, particularly sexual violence, are occurring on a widespread and systematic basis. As already noted, often this action will come after the atrocities have well and truly commenced. Nonetheless, the Security Council has primary responsibility to act on 'early warning' indicators of imminent large scale atrocities, such as ethnic cleansing and/or genocide, which are often first presented in reported human rights violations. A course open to the Security Council, but rarely pursued, is the creation of commissions to investigate and document country suspected of serious and grave human rights violations on a large scale. ${ }^{47}$ We will return to this point later.

The third and final option is actual prevention prior to the use of sexual violence. However, this requires greater attention to the conditions that exist prior to the onset of SGBV such as pervasive gender inequality and GBV in societies. This option is difficult but it tackles the 'warning-response' prevention gap that currently exists in SGBV

\footnotetext{
${ }^{45}$ Security Council Report, 'Human Rights and the Security Council: An Evolving Role', 28 January 2016. http://www.securitycouncilreport.org/special-research-report/human-rights-and-thesecurity-council---an-evolving-role.php

${ }^{46}$ The reporting of widespread and systematic SGBV in South Sudan illustrates this point, i.e. Samuel Oakford, Rape and Sexual Assault Are Being Used As a Weapon in South Sudan, Says UN, Vice News, 28 January 2015. https://news.vice.com/article/rape-and-sexual-assault-are-beingused-as-a-weapon-in-south-sudan-says-un; Amanda Sperber, In South Sudan's War, Mass Gang Rape Has Become an Everyday Weapon, Vice News, 11 March 2016. https://news.vice.com/article/in-south-sudan-gang-rape-is-a-weapon-of-war ${ }^{47}$ Security Council Report, Human Rights and the Security Council: An Evolving Role',
} 
response at the international level. This third option stems from deeper engagement with the discrimination embedded in widespread and systematic SGBV crimes. Both premises, that widespread and systematic SGBV is an opportunistic crime that stems from a climate of impunity and that it is an effective 'weapon of war' are addressed in the strategies above. However, why these political conditions (the climate of impunity and effectiveness as a weapon of war) exist in the first place are not directly or fully addressed in the responses above. The lack of institutional prohibition against sexual violence in conflict and non-conflict situations indicates a deeper crisis in how that state (or territory) appreciates the human right to physical integrity and personal liberty, and why violations of these human rights may differ according to gender norms within that society, thus disproportionately affecting women's human rights. Similarly, the use of rape, forced marriage, sex trafficking and sexual slavery to intimidate populations are effective because of generalised hierarchical gender relations that shape the construction of femininities and masculinities in all social behaviour. The gendered power relations in a given society inform the rationality of sexual violence as a 'weapon'. In other words, the utility of sexual violence is rooted in gender norms. If we want to generate responses that prevent SGBV, therefore we need to deepen our understanding of the relationship between gender inequality, gender discrimination, GBV, and widespread and systematic SGBV.

However, this prospect of introducing a gender-focused prevention condition has institutional challenges. First, the Security Council cannot be concerned with a whole range of situations where gender inequality and discrimination is pervasive. Practically there are too many states that meet these criteria and some of them serve on the Security Council. Second, the Security Council is a politically fractious entity where many disagreements are premised on the Permanent Members (in particular) disagreement on what matters that are the concern of the Council versus the General Assembly, the Human Rights Council, and so on. Human rights violations, in general, often receive this 'push back' when raised at the Security Council. Even while Women, Peace and Security has permanence on the Security Council as a thematic agenda some argue that it is precisely the narrow framing of WPS - prioritising sexual violence as a weapon in war and the end of its impunity - that has kept the (limited) WPS agenda 'safe' on the Council's Programme of Work. ${ }^{48}$

\footnotetext{
${ }^{48}$ Laura J Shepherd, 'Sex, security and superhero(in)es: From 1325 to 1820 and beyond', International Feminist Journal of Politics, 13:4 (2011), 504 - 521,
} 
The last section explores why these concerns with maintaining the political interest of the Security Council and dealing with the seemingly 'too hard' basket of pervasive gender inequality are not good reasons to avoid addressing the prior, existing conditions in society that may facilitate and trigger widespread and systematic SGBV.

\section{Solution: connecting the dots}

If we want to prevent widespread and systematic SGBV before it happens then we must critically engage with the community contexts where SGBV has been documented. We need to connect the dots between systemic gender discrimination, gender inequality and widespread and systematic SGBV based on existing cases of the latter.

In previous research, ${ }^{49}$ we examined the relationship between composite scores of gendered inequality and reports of widespread and systematic SGBV in countries listed on the SG annual reports. Using the 2012 Indices of the Organisation for Economic Cooperation and Development's (OECD) Social Institutions and Gender Index (SIGI) for 120 developing countries, we compared the average scores in this Index to the scores of those countries listed in the SG annual reports on situations of SGBV from 2012-2015.

In this article we extend that research by seeking to answer three questions. First, given the SIGI is a composite score of a country's level of gender discrimination and gender inequality over a period of time (up to five years), can we identify the particular areas of inequality more dominant in the countries that appear in the SG annual report from 2012 to 2015 compared with the countries that were not listed as situations of concerns for SGBV over the same period of time? Second, can we delve more precisely to identify particular types of inequality and discrimination - for instance, in attitudes, structures, policies and legislation - that indicate systemic patterns which may indicate a propensity for SGBV crimes in these countries? Finally, can these patterns of inequality and discrimination be identified before conflict breaks out if not prior to the onset of the atrocities themselves? That is, can we use the UN Secretary-General's list on situations of conflict to make the case to that there is a need to focus on (other) 'situations of concern' equivalent to conflict and post-conflict situations in order to develop and enhance prevention - rather than reaction - efforts.

\footnotetext{
${ }^{49}$ Sara E. Davies and Jacqui True. 'Reframing the Prevention of Conflict-Related Sexual and Gender-Based Violence', Security Dialogue, 46: 6 (2015): 495-512.
} 
The SG annual reports to the Security Council present a qualitative assessment of the widespread and systematic nature of individual and group sexual violence acts, and uses a definition of SGBV informed by the ICC's Rome Statute. ${ }^{50}$ The Inter-Agency Standing Committee (IAC) on SVAC, which supports the Office of the SRSG, assists with collating reports from UN Agencies and Offices, who record and document SGBV in conflict, in humanitarian emergencies outside of conflict including natural and environmental disasters, and other crisis situations that may be related to the drug trade, violent extremism and terrorism. ${ }^{51}$ Reports are then submitted to the IAC for consideration and potential inclusion the annual SG report on sexual violence in conflict situations. This process has meant that situations not deemed to represent a potential international threat to peace and security may be excluded. ${ }^{52}$ This explains why, at present, the list for situations of concern - 19 in 2015 (29 in total over the last three years) - is a fraction of the number of countries that could be described as 'conflict' and 'post-conflict' over the same period of time (there were 51 active conflicts in 2012, 42 in 2014). As such, we acknowledge the limitations of relying on the annual SG reports to indicate the location of all SGBV atrocities around the world. Indeed, this is a point acknowledged in the report itself. ${ }^{33}$ However, the annual reports are the only international annual record of documented sexual and gender based crimes in conflict, post-conflict, and 'situations of concern', with all the reports received and discussed by the UN Security Council. For first time in 2015 the report also included documentation of violence directed at 'sexual minorities', people who are homosexual, bisexual and/or transgender. At present, the UN Secretary-General annual report is informed by verified and corroborated evidence from within the UN system on 29 cases of states and non-state armed groups perpetrating sexual and gender-based violence between 2012 and 2015.

We compared the means for the 29 countries on the combined 2012-2015 SG list of countries where widespread and systematic sexual violence has been documented against the average score of the remaining 91 and 131 countries on the 2012 and 2014 SIGI databases respectively (the list includes countries conflict and post-conflict

${ }^{50}$ UN Secretary-General, Conflict Related Sexual Violence: Report of the Secretary-General. S/2012/33 (2012); S/2013/149 (2013); S/2014/181 (2014); S/2015/203 (2015); Office of the ICC Prosecutor, Policy article on sexual and gender-based crimes.

51 OCHA 2015

52 'Pushback' from two Security Council permanent members, China and Russia, has led to a reduction in the reporting cases not in conflict or post-conflict. See Security Council Report, Cross-Cutting Report on Women Peace and Security: Sexual Violence in Conflict and Sanctions (2014), 2. http://www.securitycouncilreport.org/atf/cf/\%7B65BFCF9B-6D27-4E9C-8CD3CF6E4FF96FF9\%7D/cross_cutting_report_2_women_peace_security_2014.pdf ${ }^{53} \mathrm{~S} / 2015 / 203,2$. 
countries). ${ }^{54}$ We report the statistical significance of the comparison of means and in a footnote, the t-statistics and probabilities. ${ }^{55}$

In the 2012 and 2014 comparisons, we found that SG listed countries had a higher than average SIGI composite gender discrimination and inequality score. This means that the countries on the SG list with documented SGBV have higher levels of gender discrimination inequality within social, political and economic realms.

The SIGI score is a composite score of five subindices (measured for each country): 1) Restricted Physical Integrity, 2) Discriminatory Family Code, 3) Son Bias, 4) Restricted Physical Liberties, and 5) Restricted Resources and Entitlements. Therefore, our next question was whether countries listed in the SG annual report showed particularly heightened gender discrimination under any of these five subindices. Conflict status is not a defining variable at this stage. We analyzed the average scores of SG listed countries and remaining SIGI countries across the five subindices that make up the SIGI composite score, for both the 2012 and 2014 Index., We found that SG listed countries, in both the 2012 and 2014 comparisons, had higher levels of gender discrimination and inequality than other SIGI countries with respect to restricted physical integrity and restricted civil liberties and that difference was statistically significant 56

\footnotetext{
${ }^{54}$ The 2012 SIGI has data on 120 countries spanning a five year time frame; the 2014 has data on 160 countries (our data omits OECD countries as they were not in the 2012 SIGI), also spanning a five year time frame. See, Organisation for Economic Co-operation and Development (OECD). 2012 SIGI: Social Institutions and Gender Index. http://www.oecd.org/dev/50288699.pdf; OECD. 2014 SIGI: Synthesis Report. http://www.genderindex.org/sites/default/files/docs/BrochureSIGI2015.pdf

55 The purpose of the t-statistics comparison is that they tell us the probability that the means are the same - that is, they provide evidence of statistical significance that the difference in the means is not random.

${ }^{56}$ For 2012 the difference of means in the overall SIGI index between SG and non-SG countries is highly statistically significant as indicated by t-test 4.513 with $\mathrm{p}=0.0$, in order words, there is a clear difference that is completely consistent with our argument. For 2014, the difference of means is highly statistically significant as indicated by t-test 4.513 with $\mathrm{p}=0.0$, in order words there is a clear difference that is completely consistent with our argument.

With respect to SIGI subindices: restricted physical integrity, the difference of means is highly statistically significant in 2012and 2014 as indicated by t-test 4.056 with $p=0.0$, and 4.416 with $\mathrm{p}=0.0$ in order words there is a clear difference that is completely consistent with our argument. With respect to restricted civil liberties, the difference of means is highly statistically significant in 2012 and 2014 as indicated by t-test 2.874 with $\mathrm{p}=0.005$, and 2.848 with $\mathrm{p}=0.005$ in order words there is a clear difference that is completely consistent with our argument. With respect to restricted resources and entitlements, the difference of means is also statistically significant in 2012and 2014 as indicated by t-test 2.662 with $p=0.009$, and 3.596 with $p=0.01$ in order words there is a clear difference that is completely consistent with our argument.
} 
What does restricted physical integrity mean, however? How it is measured and representative of a country's gender inequality? What are the particular variables the SIGI measures to ascertain 'restricted physical integrity' that showed greater gender discrimination and inequality among the SG listed countries than the remaining SIGI countries. The 2012 and 2014 restricted physical integrity subindices are relatively similar with seven variable - with the 2014 SIGI adding one more variable - access to abortion. The presence of general to specific legislation against rape (variable 1), domestic violence (variable 2), sexual harassment (variable 3), and female genital mutilation (FGM, variable 4), make up the first part of total restricted physical integrity score. The stronger legislation the 'weaker' the SIGI restricted physical integrity score (scale 0 [strong] to 1 [weak]). The remainder of this score is divided into attitudes and resources to protect the body such as women's attitudes towards domestic violence (variable 5), the percentage of women who have experienced a lifetime of intimate partner physical and/or sexual violence (prevalence rate) (variable 6), the reproductive autonomy of women (variable 7) and in 2014 SIGI, access to abortion (variable 8.)

If a focus on prevention of SGBV requires engagement with the prior gender inequalities in social, political and economic conditions, what do the SIGI comparisons reveal? First, comparisons between non-listed (SIGI) countries and SG listed countries reveals that gender inequality is, on average, greater in countries where SGBV is likely to occur (situation of concern), has occurred (post-conflict situation) and is occurring (conflict situation). This is not because of the presence of conflict because the remaining SIGI countries not on the SG list include countries embroiled in conflict.

Second, which dimensions of gender inequality most increase the likelihood of SGBV across cases? We found that restricted physical integrity is consistently present at higher levels in SG listed countries than other SIGI countries. In particular, the lack of laws that protect the individuals from gender-based violence, and uphold the right to physical autonomy, are both weakly represented in SG list countries. SG list countries with documented sexual violence are also more likely to have a higher proportion of women who accept that a husband/partner is justified in beating his wife/partner is justified under certain circumstances.

For countries in the SIGI 2014, that are not situations of concern for sexual violence the mean value of domestic violence laws is 0.452 , close to the SIGI coding of 0.5 , which indicates that on average countries have only general legislation against domestic 
violence in place or specific legislation that is judged to be inadequate (e.g. it may not include marital rape). An important finding here is that countries on SG list for sexual violence with a mean value of domestic violence laws as 0.6759 are much more likely to have no legislation at all relating to domestic violence. This analysis concurs with our argument that a pre-existing culture of impunity toward forms of sexual and genderbased violence, which includes intimate-partner/domestic violence is a facilitating societal condition for widespread and systematic sexual violence. In the context of a global movement promoting the diffusion of laws against domestic violence, ${ }^{57}$ countries that either do not have such laws or inadequate legal frameworks are countries where the state has failed to address its responsibility to protect against and prevent SBGV wherever it occurs and is therefore likely complicit in the use of sexual violence.

For countries in the SIGI 2014 that are not situations of concern for sexual violence the mean value of domestic violence attitudes is 0.34071 , which indicates the average percentage of women who agree that domestic violence is justified. A key finding here is that countries on SG list for sexual violence are more likely to have a higher proportion of women who accept domestic violence. The mean score for countries on the list is 0.5402 , suggesting that in the SG list countries on average a majority, of women accept the use of domestic violence This difference is very statistically significant. 58

Third, the particular variables within the restricted physical integrity subindices that trend higher for SG listed countries are not what we might most expect, for instance, the absence of rape laws, sexual harassment laws, or reproductive rights. Rather, it is the lack of - in or weak - domestic violence legislation as well as attitudinal acceptance of intimate partner violence that most registers in SG list countries where SGBV is likely to occur and/or has occurred compared non-SG list SIGI countries. Thus, no or weak domestic violence laws and acceptance of physical or other harm by an intimate partner represents risk factors for SGBV for women and girls. This finding gives us insight into the reasons why reporting of GBV is low - because there is no law mandating it and

\footnotetext{
${ }^{57}$ Mala Htun and S. Laurel Weldon, 'The Civic Origins of Progressive Policy Change: Combating Violence against Women in Global Perspective, 1975-2005',, American Political Science Review 106 (2012), 548-569.

58 With respect to the variables in the SIGI restricted physical integrity subindices, the difference of means in SG and non-SG list countries is highly statistically significant in 2012 and 2014 with respect to the strength of domestic violence laws, as indicated by t-test 4.125 with $\mathrm{p}=$ 0.0 , and 3.076 with $p=0.003$ in order words there is a clear difference that is completely consistent with our argument; and with respect to domestic violence attitudes is statistically significant in 2012 as indicated by t-test 2.196 with $\mathrm{p}=0.40$, and 3.076 with $\mathrm{p}=0.003$ and highly statistically significant in 20143.745 and $\mathrm{p}=0.0$ in 2014.
} 
widespread acceptance of SGBV by intimate partners - in returning to the tip of the iceberg point at the beginning of the article. Moreover, it highlights the real challenges involved in identifying newly emerging situations of SGBV. A key implication of this analysis of these attitudinal and lack of legal justice risk factors is that awareness raising about intimate partner violence, gender based violence, and the unacceptability of such violence are crucial measures towards preventing SGBV.

A fourth, further concern of our focus on prevention of SGBV is to understand the relationship between conflict situations, post-conflict situations and 'situations of concern', that is, where violations are imminent but cannot be categorised as a conflict or post-conflict situation. The protests in Egypt and the Boko Haram led kidnappings in Nigeria are two examples of reported 'situations of concern' on the SG list. However, there are few listings of these situations compared with conflict and post-conflict situations. The 2012 report had the longest list to date of these types of situations. Understanding differences in the average levels of gender discrimination and inequality (SIGI score) among these situations is one step further toward understanding their relationship to patterns of violence and conditions of safety in general. For instance, the presence of conflict may be exaggerating the SIGI scores of SG listed countries. Are there differences among the SG listed countries on the 2012 and 2014 SIGI scores when we disaggregated those countries compare by those in conflict, post-conflict countries, and listed as situations of concern? Based on the 2012 data, there were statistically significant differences among the types of SIGI countries, and particularly so in the area of restricted physical integrity. Importantly, the countries listed by the SG as situations of concern for SGBV had a higher average gender discrimination score for restricted physical integrity than all other types of SIGI countries except those currently in experiencing conflict. ${ }^{59}$ In 2014 there was no situation of concern countries listed to compare.

Given our findings that a country's indicators of particularly high restricted physical integrity may be crucial 'early warning ' mechanisms for SGBV, identifying high-risk situations where interventions to assist with strengthening domestic violence laws and awareness about gender based violence would serve not only to achieve human rights goals, but they may actually prevent the escalation of sexual violence. In practice, this

\footnotetext{
${ }^{59}$ However, there is minimal difference in the average gender discrimination score for countries that are situations of concern at 3.599 compared conflict countries 3.776 - and the average discrimination score (2.331) for SIGI countries that are not conflict, post-conflict or situations of concern
} 
means that paying attention to countries that score higher than average in the SIGI restricted physical integrity subindex may point us towards situations where the 'warning-response' gap ${ }^{60}$ could be addressed in the area of SGBV. If we adopt an even higher threshold than above average SIGI score for physical integrity, and place it at the average score for the 2012 SG listed situations of concern, we immediately start to identify a number of countries in the 2014 SIGI list where there are high rates of restricted physical integrity that merit attention - namely, Bangladesh, Burkina Faso, Burundi, Egypt, Ethiopia, Eritrea, Gambia, Kenya, Pakistan, Timor-Leste, Tajikistan,

\section{Conclusion}

After the 2015 Global Study on the Implementation of UNSCR 1325, advocates argued that the subsequent SCR 2242 'barely addressed the conflict prevention measures identified in the study'.61 Across the three reviews of Peace Operations, Peacebuilding and WPS in 2015, a similar finding was echoed - the failure of the UN in the area of conflict prevention. As the Security Council Report recently noted, for the Security Council 'human rights violations are often among the first warning signs of a looming conflict; they may be part of a conflict's root causes; and they are almost invariably a feature of the conflict', 62 but the Security Council has found it notoriously difficult to keep track of and document these crimes in order to do something about them before the atrocities commence. The challenge for prevention is how to bridge that gap between what we theoretically and empirically know about past cases of atrocities and what can practically be addressed before future atrocities to prevent them.

We have argued that we need connect the dots between our knowledge of gendered inequality (and violence) and what we know about the conditions in past cases of widespread and systematic sexual and gender-based violence. Can we extrapolate from these past cases to develop indicators for early warning of future events? Yes we can, though for some situations of concern we will need to know much more about the status of gender inequality and discrimination and social, institutional, political and economic changes affecting gender inequality and discrimination because that status is dynamic. Indeed, the lack of knowledge and awareness of gendered discrimination and violence in

\footnotetext{
${ }^{60}$ George and Holl, The Warning-Response Problem and Missed Opportunities in Preventive Diplomacy.

${ }^{61}$ Lucía Mazzuca,Towards a fuller implementation of the Women, Peace and Security Agenda, Centre for Women Peace and Security, LSE, January 2016. http://www.lse ac.uk/WomenPeaceSecurity/pdf/2016/01MazzucaGlobalStudy.pdf 62 Security Council Report, Human Rights and Security Council, 2.
} 
some countries and situations of concern is symptomatic; it is itself a condition for the perpetration of SGVB atrocities.

In this article, we suggest that paying close attention to gender inequality and the particular practices of gender inequality in societies - as well as dramatic changes in these practices - provides crucial indications of where to begin dedicating resources and time for the purpose of long-term prevention. The introduction of gender-inequality as a prevention condition that is complimentary to but distinct from structural, direct and escalation conditions will be an investment with a win-win benefit. Whether atrocities take place or not, gender-focused early warning will enhance the protection of typically marginalised and vulnerable populations whose rights and protection (and indeed right to protection) are presently lacking and stop systematic and widespread atrocities from ensuing. 